\title{
Spawning Biology and Induced Breeding of freshwater catfish Mystus dibrugarensis:
}

\section{An approach to conservation}

Bhenila Bailung* and S. P. Biswas, Life Sciences department, Dibrugarh University, Assam, India email: bhenila.bailung@gmail.com

\begin{abstract}
Spawning biology of hormone induced bagridae catfish, Mystus dibrugarensis was observed in captive condition. Active involvement of male in courtship after 5-9 hr. of hormone administration was observed. Different doses of ovaprim $0.4,0.6,0.8,1.0 \mathrm{ml} / \mathrm{kg}$ were used by maintaining 1:1, 2:1 and 3:1 ratio of M:F. All female successfully bred in all the condition in more or less amount. Overall $24.5-77.5 \%$ fertilization and $12-76 \%$ hatching rate was observed. However, considering the rate of fertilization, and hatching success in the present case, at $0.8 \mathrm{ml} / \mathrm{kg}$ body weight and sex ratio $2 \hat{\jmath}: 1 q$ seems ideal for induced breeding of $M$. dibrugarensis. Apart from induced breeding certain reproductive aspects were also studied in the present experiment.
\end{abstract}

Key words: bagridae, breeding, reproductive aspects, spawning

\section{INTRODUCTION:}

North East India is a huge reservoir of fresh water fish germplasm and considered as a hot spot of fresh water fish biodiversity (Mahanta et al., 2001). Over 200 fish species have been reported from the Brahmaputra drainage system so far (Sen, 2000), of which 78 species have been identified as highly suitable for aquarium rearing (Biswas et al., 2007). Due to various factors like overexploitation, habitat destruction these species facing lots of threat as a result there no. decreases day by day. Mystus dibrugarensis (Chaudhuri, 1913) is a freshwater riverine catfish having ornamental value is one of them. According to IUCN it is considered under least concern, but unfortunately it is found in certain pockets of upper Brahmaputra basin mainly in Dihing River (Bailung, 2014). Captive breeding of fish, is a widely used management tool in attempts to restore and conservation of the wild populations of endangered and endemic species and simultaneously to supplement and enhance yields for fisheries (Fleming, 1994). Considering the potential of fish species, captive breeding can serve the purpose for introducing the indigenous species in the global market 
generating foreign exchange (Das and Kalita, 2003). Therefore, to save species from its extinction through induced breeding a complete knowledge about its biology including breeding behaviour, fecundity, fertilization and hatching through captive breeding is also essential (Islam et al., 2011). Successful technology for breeding and rearing of a species in captivity is the prerequisite for rehabilitation of natural stocks as well as for culture. Therefore, standardization of breeding protocol suitable to the climate condition of Assam will definitely boost the entrepreneurs of native fish species.

Different workers worked on spawning season and induced breeding of Mystus species such as Ray, 2005 (Mystus gulio); Islam et al., 2011 (Mystus vittatus); Gupta et al., 2013 (Mystus tengara). But till date there is no any information about induced breeding of Mystus dibrugarensis. In view of the paucity of knowledge on the breeding practice and its occasional occurrence, Mystus dibrugarensis is selected for a detailed study.

\section{METHODS \& METHODOLOGY}

Live and healthy species $M$. dibrugarensis were collected from Dihing River of Dibrugarh district, Assam, India from its confluence with almighty R. Brahmaputra i.e. Dihingmukh $\left(27^{\circ} 15^{\prime} 41^{\prime \prime}\right.$ $\mathrm{N}$ and $94^{\circ} 42^{\prime} 10^{\prime /} \mathrm{E}$ ) of upper Assam from January 2014 to August 2016.

Sex differentiation of $M$. dibrugarensis was done by careful visual inspection of the presence of genital papilla and genital pore. Sex-ratio was determined by separation of specimen from the monthly collection into male and female groups and counting the total number of specimen in two sex groups by following Mahmood et al. (2011). Chi-square test $\left(\chi^{2}\right)$ was done to test the ratio difference was significant or not, assuming that the ratio of male to female in the population to be 1:1. Routine assessment of gonadal development is normally done by assessing individuals to stages by characters which can be differentiated with the naked eye. Depending on the morphology of 
gonads and portion of abdominal cavity occupied by gonads, both testicular and ovarian cycle of male and female respectively were done by following Nikolsky (1963).

Ovaries from mature specimens were only considered for fecundity studies. Sub-sampling method (Bagenal, 1957) was employed for calculating fecundity. Likewise relative fecundity was estimated by dividing the absolute fecundity with total body weight (Biswas, 2002). Ovadiameter measurement was done with the help of stereo microscope and Leica software.

Breeding trails were done from late April to July of three consecutive years (2014-2016). The collected specimens were subjected through a 30-day quarantine period as per (Louis, 1995). Brooders were stocked in separate earthen ponds $(3 \times 3 \times 1 \mathrm{~m})$ having sandy bottom from January to March. In April, specimen were transferred to fibre circular tank $(135 \mathrm{D} \times 35 \mathrm{H} \mathrm{cm})$ and were kept there until breeding experiment was conducted. Tanks were provided good quality of water, with the facility of water circulation, aeration and replenishment. A mixture of sand and small gravel of about $4 \mathrm{~cm}$ was filled at the bottom and some aquatic plants like water hyacinth (Eichhornia crassipes) and Pistia was placed to create a spawning habitat. They were supplied with natural food like live earthworm, mosquito larvae, small insect, ants, and plankton as well as artificially formulated food such as dried Tubifex, prawns, Artemia and fishes twice daily at $5 \%$ of their body weight. The physico-chemical parameters of water was determined as per APHA (1998) and digital gadgets.

\section{RESULTS \& DISCUSSION:}

Sex differentiation in $M$. dibrugarensis is relatively simple. Male having a soft conical projection in front of the anal fin that termed as genital papilla. In female this genital papilla was absent whereas they possess a round genital opening and swelling abdomen when they were matured. This observation was also recorded by various workers in other Mystus species (Bhatt, 1971a and b; Ng, 2001; Musa and Bhuiyan, 2007; Darshan et al, 2011 and 2013). Sex-ratio provides information 
on the proportion of male and female fish in the population. The overall sex-ratio was 0.932:1 (M: F), significantly tilted towards female $\left(\chi^{2}=5.87\right.$, at $\left.\mathrm{P}_{0.01}\right)$. Here, out of total specimens examined, $45.7 \%$ was males and $54.2 \%$ was female. Monthly distribution of sexes fluctuated significantly in favor of female in April, May, June, July is may be because of their heavier weight due to their full gonadal development (Biswas, 1984). This observation was similar with the Bhatt (1971); Rao and Sharma (1984). Hypoxia or low dissolved oxygen levels have been shown to favors male dominance in populations due to the effect on sexual development and sex differentiation (Shang et al. 2006). This may be the reason of male dominance during winter months.

Depending on the morphology of testis and ovary, portion of abdominal cavity occupied by gonads, at different developmental period and size of the intra-ovarian oocytes, five maturity stages of gonad have been identified (Nikolsky, 1963) namely stage I: Immature; stage II: maturing; stage III: Mature, stage IV: Ripe and stage V: Spent. Gupta \& Banerjee (2013) and Basu et al. (2015) mentioned five maturity in Mystus tengara and $M$. vittatus. The gonads in immature stage is highly rudimentary and pinkish in colour. In maturing stage gonads occupied about half of the body cavity and vessels started to developed. Gonads in mature stages occupied $3 / 4^{\text {th }}$ of the body cavity with well-developed blood vessels. Eggs were also clearly seen in ovary through naked eyes. As the maturity progressed, the gonads became thicker, changed to yellowish or reddish in color due to development of blood vessels and it occupied almost the entire ventral cavity. Gonads became highly reduced in size and flaccid in spent stage. Here, development of finger like projection was observed in testes from maturing stage which was found gradually increased in size and volume as the maturity progressed. Gupta and Banerjee (2013) called this projection as testicular in M. tengara. Ripe females were found from April to August with a peak in June whereas ripe males were observed from March to August with the highest percentage encountered in May. Monthly percentage distribution of females and males at various maturity stages are given in Table 1. 
Table 1: Monthly occurrence of female in different stages of maturation

\begin{tabular}{|c|c|c|c|c|c|c|c|c|c|c|c|c|}
\hline \multirow{2}{*}{$\begin{array}{l}\text { Mont } \\
\text { h }\end{array}$} & \multirow{2}{*}{$\begin{array}{l}\text { No. of } \\
\text { female }\end{array}$} & \multicolumn{5}{|c|}{ Maturity stages in females (\%) } & \multirow{2}{*}{$\begin{array}{l}\text { No. of } \\
\text { male }\end{array}$} & \multicolumn{5}{|c|}{ Maturity stages in females (\%) } \\
\hline & & $1^{\mathrm{st}}$ & $2^{\text {nd }}$ & $3^{\text {rd }}$ & $4^{\text {th }}$ & $5^{\text {th }}$ & & $1^{\text {st }}$ & $2^{\text {nd }}$ & $3^{\text {rd }}$ & $4^{\text {th }}$ & $5^{\text {th }}$ \\
\hline Jan & 43 & 44.1 & 55.8 & -- & - & -- & 50 & 56.0 & 34.0 & 10.0 & -- & -- \\
\hline Feb & 63 & 14.2 & 57.1 & 28.5 & -- & -- & 97 & 23.7 & 44.3 & 31.9 & -- & -- \\
\hline Mar & 24 & -- & 41.6 & 58.3 & -- & -- & 16 & --- & 25.0 & 68.7 & 6.25 & --- \\
\hline Apr & 29 & --- & 6.89 & 44.8 & 51.7 & -- & 14 & --- & 14.2 & 35.7 & 50 & --- \\
\hline May & 32 & --- & --- & 25.0 & 75.0 & -- & 17 & --- & --- & 23.5 & 70.5 & 5.88 \\
\hline Jun & 26 & -- & --- & 3.84 & 80.7 & 15.3 & 13 & --- & --- & 7.69 & 69.2 & 23.0 \\
\hline Jul & 38 & -- & --- & --- & 68.4 & 31.5 & 22 & --- & --- & --- & 63.6 & 36.3 \\
\hline Aug & 28 & 14.2 & -- & --- & 17.8 & 82.1 & 21 & --- & --- & --- & 19.0 & 80.9 \\
\hline Sept & 33 & 57.5 & -- & --- & --- & 42.4 & 24 & 16.6 & -- & --- & --- & 83.3 \\
\hline Oct & 23 & 91.3 & 8.69 & --- & -- & 23.1 & 28 & 78.5 & --- & --- & --- & 21.4 \\
\hline Nov & 38 & 92.1 & 7.89 & -- & -- & -- & 41 & 75.6 & 24.3 & --- & --- & --- \\
\hline Dec & 16 & 81.2 & 18.7 & -- & -- & --- & 28 & 71.4 & 28.5 & --- & --- & --- \\
\hline
\end{tabular}

The development of gonad can be represented by an index called gonadosomatic ratio (GSR) which provides information about spawning season of a particular species. Progressive increase of GSR value in both the sexes from April indicated that its breeding period starts from April. High

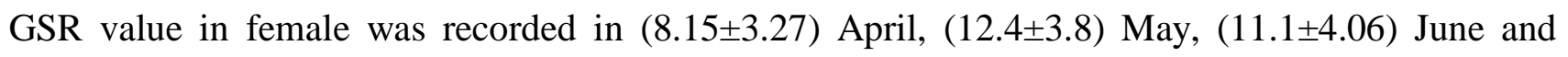
(6.58 \pm 0.68$)$ July. Similarly, high GSR in male was (1.21 \pm 0.73$)$ April, (1.66 \pm 0.41$)$ May, (1.49 \pm 0.45$)$ June and (1.27 \pm 0.44$)$ July. The ova diameter of $M$. dibrugarensis progressively increased from January onwards and maximum size of intra-ovarian egg was observed in May (1.28 \pm 0.24$)$ to July $(1.31 \pm 0.17)$. This suggested that these months as peak breeding period of the selected species. Declination in the GSR value from August indicated that the spawning is over by August in $M$. dibrugarensis. This result was similar with the finding of Sarker et al. (2002) and Basu et al. (2015).

Fecundity provides information about reproductive potential of the spawning stock. The maximum absolute fecundity $(12338.57 \pm 1241.04)$ was found in the length group of $11.5-14 \mathrm{~cm}$ and the minimum $(6965 \pm 889.38)$ in $6.5-9.0 \mathrm{~cm}$. The fecundity was found increased with the increase in length of the M. dibrugarensis that similar with the findings of Azadi et al. (1987), Siddique et al. 
(2008), Islam et al. (2011) and Gupta (2013). Monthly, highest absolute fecundity (7026 \pm 2200$)$ and relative fecundity $(830.2 \pm 167.8)$ was found in April and lowest absolute fecundity $(411 \pm 154.7)$ and relative fecundity $(44 \pm 22.7)$ in August. They were categorized as single spawner because it was found that they did not release the remaining eggs which were found reabsorbed later. Similarly Prabhu (1956), Qasim and Qayyum (1961), Bhatt (1971a), and Rao and Sharma (1984) reported $M$. vittatus as single spawner, Gupta and Banerjee (2013) also reported M. tengara as single spawner.

For induced breeding, total length and weight of the fish were measured nearest to $1.0 \mathrm{~mm}$ and $0.1 \mathrm{~g}$, respectively. Hormone "ovaprim" was induced below the pectoral fin with $1 \mathrm{ml}$ syringe at a dose of $0.4-1.0 \mathrm{ml} / \mathrm{kg}$ during evening time by maintaining 1:1, 2:1 and 3:1 ratio of M:F. After 5-9 hr. male was observed more actively involved in courtship. The same phenomenon was also reported by Alam et al. (2006) and Islam et al. (2011). Spawning occurred after 2-3 hr. of latency period and continued for 1-2 hr (Bailung and Biswas, 2014). Eggs adhesive, (0.9 \pm 0.2$) \mathrm{mm}$ in size, creamy or yellowish in color. Fertilization rate $24.4 \%-55.6 \% ; 30 \%-77.5 \%$ and $26.5 \%-65.7 \%$ and hatching rate $20-66 \% ; 22-76 \%$ and $12-58 \%$ was observed in $1: 1,2: 1$ and $3: 1$ ratio of $\mathrm{M}: \mathrm{F}$ respectively. Likewise, overall 20.4-54.3\%; 24.4-67.06; 31.1-77.54 and 26.5-70.3\% fertilization was observed in $0.4,0.6,0.8$ and $1.0 \mathrm{ml} / \mathrm{kg}$ hormone dose. However, considering the rate of fertilization,

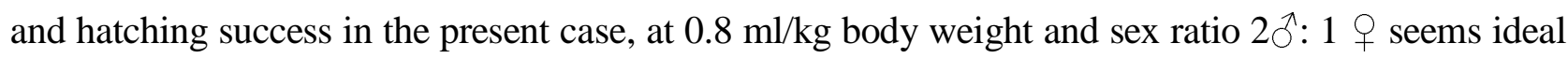
for induced breeding of M. dibrugarensis. Similar finding was reported by Islam et al. (2011).

Table 2: Physico-chemical parameter of water tank

\begin{tabular}{|c|c|c|c|c|c|}
\hline Tank & $\mathrm{pH}$ & $\mathrm{DO}(\mathrm{mg} / \mathrm{L})$ & $\mathrm{FCO}_{2}(\mathrm{mg} / \mathrm{L})$ & Alk. $(\mathrm{mg} / \mathrm{L})$ & WT $\left({ }^{0} \mathrm{C}\right)$ \\
\hline Breeding & $7.1-7.3$ & $10.2-11.6$ & $2.20-3.52$ & $52-57$ & $27-29$ \\
\hline Rearing & $7.4-7.51$ & $7.4-7.7$ & $4.2-4.5$ & $46-54$ & $25-27$ \\
\hline
\end{tabular}


In the present study, M. dibrugarensis also showed more or less similar pattern of survival rate like as other Mystus species. Pond plankton and boiled chicken egg yolk mixed with water were provided to the hatchlings from $2^{\text {nd }}$ week onwards. After 15 days they were fed with finely macerated dried Tubifex when they were about three weeks. After 30 day, they were provided with chopped dried Tubifex, prawn, earthworm, insect larvae etc. The average rate of survival at different period was presented in Table 3.

Table 3: Survival and growth rate of hatchlings

\begin{tabular}{|c|c|c|c|c|c|c|}
\hline Age of fish & $5^{\text {th }}$ day & $10^{\text {th }}$ day & $15^{\text {th }}$ day & $20^{\text {th }}$ day & $30^{\text {th }}$ day & Fingerlings \\
\hline Stocking density (no.) & 100 & 55 & 23 & 16 & 14 & 14 \\
\hline Survivability (\%) & 55 & 41.8 & 69 & 87 & 100 & 86 \\
\hline Length (mm) & $6.2 \pm 0.81$ & $11 \pm 3.31$ & $12.1 \pm 1.05$ & $15.3 \pm 3.07$ & $21.1 \pm 2.04$ & $49 \pm 3.03$ \\
\hline
\end{tabular}

\section{CONCLUSION:}

Fish in captivity may not always reproduce at the most favorable time. In this situation, proper dose of hormones play a critical role in the reproductive processes (Singh and Gupta, 2011). In the present study, was also found to breed naturally during April-July. Identical breeding period was also reported for M. vittatus by Arockiaraj et al. (2004) and Basu et al. (2015) and also in M. tengara (Rastogi and Saxsena, 1968). Mukherjee et al. (2002) able to breed M. gulio with ovaprim at dose of 2.5 $\mathrm{ml} / \mathrm{kg}$ and at $0.4 \mathrm{ml} / \mathrm{kg}$ dose of 'ovatide' in M. armatus. Sarkar et al. (2005) reported induced spawning of O. pabda with single dose of ovaprim at $0.5 \mathrm{ml} / \mathrm{kg}$ resulting in $84-91 \%$ fertilization rate and $65-66 \%$ hatching rate. Alam et al. (2006) found fertilization rate of $81-85 \%$ and hatching of $71-73 \%$ suggested that M. gulio also can successfully be bred in captivity using a single dose of $1-2 \mathrm{ml} / \mathrm{kg}$ body weight of both male and female. 
Therefore, it may be concluded that in proper hormone dose, sex-ratio, and environmental condition the selected species can be successfully breed in captive condition. Their hardy nature, body design, wide food spectrum, acceptance of commercial pellets in captive conditions, ornamental value and high consumer preference for its taste, this endemic rarity ichthyofauna M. dibrugarensis make it a high value potential candidate for freshwater commercial aquaculture systems which is also an approach to conservation of this species.

Acknowledgement: The authors gratefully acknowledge the Department of Life Sciences, Dibrugarh University for the laboratory facilities used during the study. Financial assistance from NFDB, Hyderabad is highly acknowledged.

\section{REFERENCES:}

Alam, M. J., M. Begum, M. A. Islam and H. K. Pal (2006): Spawning behaviour and induced breeding of an estuarine catfish, Mystus gulio (Ham.). Bangladesh Journal of Fishery Research, 10(2): 101109.

A.P.H.A. (1998): Standard methods for estimation of water and waste and water, $20^{\text {th }}$ edition, American Public Health Association, Washington D.C., USA. 1193p.

Arockiaraj, A.J., M. A. Haniffa, S. Seetharaman and S. Singh (2004): Cyclic Changes in gonadal maturation and histological observations of threatened freshwater catfish "Narikelu" Mystusmonotonus (Jerdon, 1849). Acta Ichthyological Et Piscatoria, 34(2): 253-266.

Azadi, M. A., M. A. Islam and S. R. Dev (1987): Some aspects of the biology of Mystus vittatus (Bloch): I. Food and feeding habits and fecundity. Proceedings of $12^{\text {th }}$ Annual Bangladesh Science Conference, Bangladesh Association for the Advancement of Science, Dhaka, 36p.

Bagenal, T. B. (1957a): The breeding and fecundity of the long rough dab, Hippoglossoides platessoides (Fabr.) and the associated cycle in condition. Journal of Marine Biological Association of United Kingdom, 36: 339-375.

Bailung, B. and S. P. Biswas (2014): Checklist, status and role of fish diversity as a measure of alternative livelihood in Dihing river basin, Assam. International Journal of Applied Biology and Pharmaceutical Technology, 5(3): 1-4. 
Bailung, B. and S. P. Biswas (2014): Successful induced breeding of a bagrid catfish, Mystus dibrugarensis in captive condition. Journal of Aquaculture Research and Development, 5(7): doi. 10.4172/2155-9546.1000281.

Basu, A., S. Roy, I. Sarkar, K. Dhara and S. Datta (2015): Seasonal changes in ovarian maturation of an Asian catfish, Mystus vittatus (Bloch, 1797) in captivity. Biolife, 3(3):620-628.

Biswas, S. P. (2002): Fundamentals of Ichthyology. Narendra Publishing House, Delhi, 392p.

Biswas, S. P., J. N. Das, U. K. Sarkar and W. S. Lakra (2007): Ornamental Fishes of North East India: An Atlas. NBFGR (ICAR) Publication, Lucknow, 111p.

Biswas, S. P., S. A. Nasar and K. Chatterjee (1984): Inter and Intra specific comparisons on some aspects of the reproductive biology of the two carps Labeo pangusia (Ham.) and Labeo dero (Ham.), Archives of Biological Science (Bruxelles), 95: 11-27.

Bhatt, V. S. (1971a): Studies on the biology of some freshwater fishes. Part -V. Mystus vittatus (Bloch). Journal of the Bombay Natural History Society, 67 (2): 194-211.

Bhatt, V. S. (1971b): Studies on the biology of some freshwater fishes. Part -VI. Mystus cavasius (Hamilton). Hydrobiologia, 38(2): 289-302.

Chaudhuri, B. L. (1913): Zoological results of the Abor Expedition, 1911-12. XVIII. Fish. Records of the Indian Museum (Calcutta), 8: 243-257.

Darshan, A., P. C. Mahanta, A. Bharat and P. Kumar (2013): Redescription of the striped catfish Mystus tengara (Hamilton, 1822) (Siluriformes: Bagridae). Journal of Threatened Taxa, 5(1): 35363541 .

Darshan, A., W. Vishwanath, P. C. Mahanta and A. Barat (2011): Mystus ngasep, a new catfish species (Teleostei: Bagridae) from the headwaters of Chindwin drainage in Manipur, India.Journal of Threatened Taxa, 3(11): 2177-2183.

Das, S. K. and N. Kalita (2003): Captive breeding of peacock eel, Macrognathus aculeatus. Aquaculture Asia, 8: 17-21.

Fleming, I. A. (1994): Captive Breeding and the conservation of wild salmon populations. Conservation Biology, 8: 886-888.

Gupta, S. and S. Banerjee (2013): Studies on reproductive biology of Mystus tengara (Ham.-Buch., 1822), a freshwater catfish of West Bengal, India. International Journal of Aquatic Biology, 1(4): 175-184.

Islam, S., S. Shah and L. Rahi (2011): Study of fecundity and induced breeding of Mystus vittatus. Bangladesh Journal of Zoology, 39 (2): 205-212.

Louis J. D., S. Srinivas, B. R. WhitakerC. Andrews, B. Hecker, A. S. Kane and R. Reimschuessel (1995): Guidelines for the Care and Use of Fish in Research. Institute for Laboratory Animal Research, 57(20): 155-173. 
Mahanta, P. C., L. K. Tyagi, D. Kapoor and A. G. Ponniah (2001): Integration of fish biodiversity conservation and development of fisheries in North-East region: Issue and approach. In: Integration of Fish Biodiversity Conservation and Development of Fisheries in North-East region through Community Participation. NBFGR Publication, Lucknow, 1-18.

Mahmood, K., Z. Ayub and G. Siddique (2011): Sex-ratio, maturation and spawning of Indian ilisha, ilisha melastoma (clupiformes: pristigasteridae) in coastal waters of Pakistan (northern Arabian Sea). Indian Journal of Geo-Marine Science, 40(4): 516-521.

Mukherjee, M., A. Praharaj and S. Das (2002): Conservation of endangered fish stocks through artificial propagation and larval rearing technique in West Bengal, India. Aquaculture Asia, 7 (2): 8-11.

Musa, A. S. M. and A. S. Bhuiyan (2007): Fecundity on Mystus bleekeri (Day, 1877) from the River Padma near Rajshahi city. Turkish Journal of Fisheries and Aquatic Sciences, 7: 161-162.

Ng H. H. (2001): Mystus punctifer, a new species of Bagrid catfish (Teleostei: Siluriformes) from northern Sumatra. The Raffles Bulletin of Zoology, 49 (2): 355-358.

Nikolsky, G. V. (1963): Ecology of Fishes. Academic Press, London and New York, 352p.

Prabhu, M. S. (1956): Maturation and intra ovarian eggs and spawning periodicities in some fishes. Indian Journal of Fisheries, 3(1): 59-90.

Qasim S. Z. and A. Qayyum (1961): Spawning frequencies and breeding seasons of some freshwater fishes with special reference to those occurring in the plains of Northern India. Indian Journal of Fisheries, 8(1):24-43.

Rao, T. A. and S. V. Sharma (1984): Reproductive biology of Mystus vittatus (Bloch) from Guntur, Andhra Pradesh. Hydrobiologia, 119 (1): 21-26.

Rastogi, R. K. and P. K. Saxsena (1968): Annual changes in the ovarian activity of catfish, Mystus tengara (Ham.) (Teleostei). Japanese Journal of Ichthyology, 15(1): 28-35.

Ray, P. K. (2005): Induced breeding and larval rearing of brackish water catfish, Mystus gulio in salinityfree water. Fishing chime, 25:1-4.

Sarkar, U. K., P. K. Deepak, R. S. Negi, S. Paul and S. P. Singh (2005): Captive breeding of an endangered fish Ompok pabda (Hamilton-Buchanan) using different doses of ovaprim. Journal of Inland Fisheries Society of India. 37(2): 37-42.

Sarker, P., H. Pal and M. M. Rahman (2002): Observation on the fecundity and gonado- somatic index of Mystus gulio in brackish waters of Bangladesh. Journal of Biological Sciences, 2(4): 235-237.

Sen, N. (2003): Occurrence, distribution and status of diversified fish fauna of north east India. In: Fish Biodiversity of North-East India (Eds. Ponniah, A. G. and Sarkar, U.K.). NATP Publication, NBFGR, Lucknow, 2: 31-48.

Shang, E. H. H., R. M. K. Yu, and R. S. S. Wu (2006): Hypoxia affects sex differentiation and development, leading to a male-dominated population in Zebra fish Danio rerio. Environmental Science and Technology, 40: 3118-22. 
bioRxiv preprint doi: https://doi.org/10.1101/229377; this version posted December 5,2017 . The copyright holder for this preprint (which was not certified by peer review) is the author/funder, who has granted bioRxiv a license to display the preprint in perpetuity. It is made available under aCC-BY-ND 4.0 International license.

Singh, R. and A. K. Gupta (2011): Control mechanism for induced spawning in fiah reproduction. Journal of Experimental Zoology, 14(1): 1-13. 


\section{PLATE I}

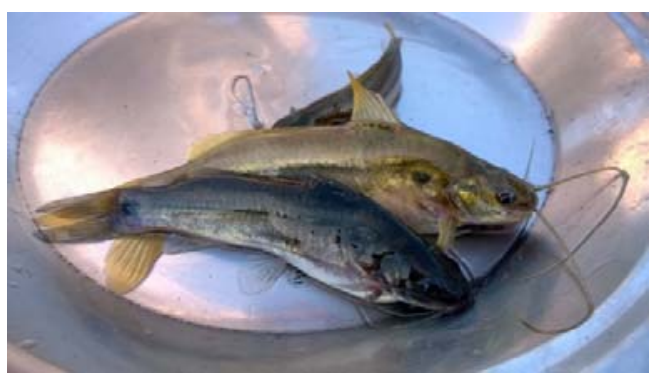

Fig 1A: Female brooders of M. dibrugarensis

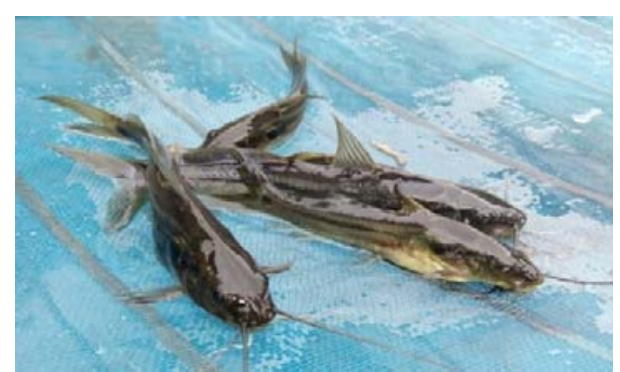

Fig 1B: Male brooders

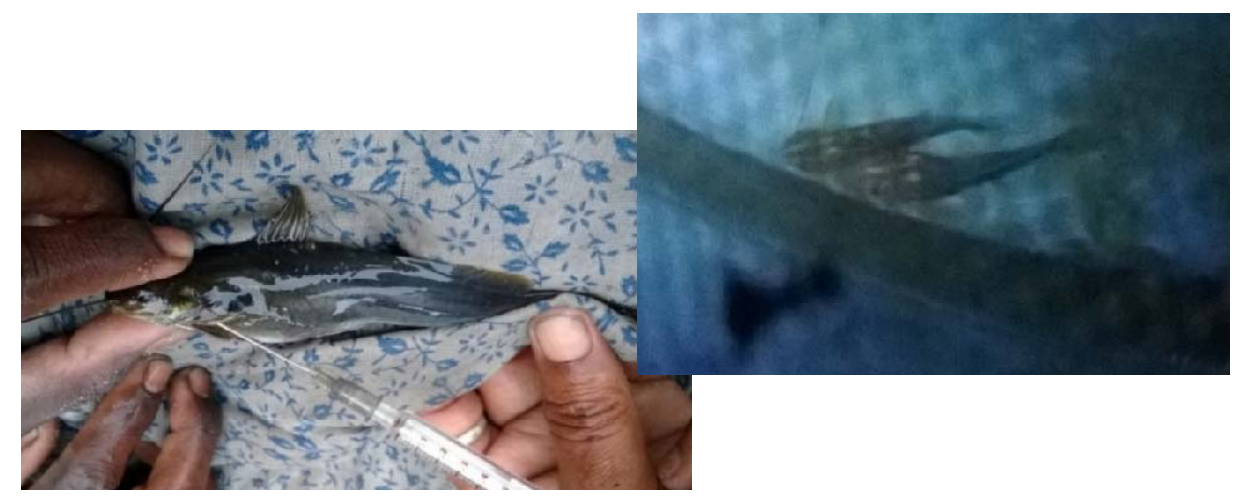

Fig 2: Hormone injection

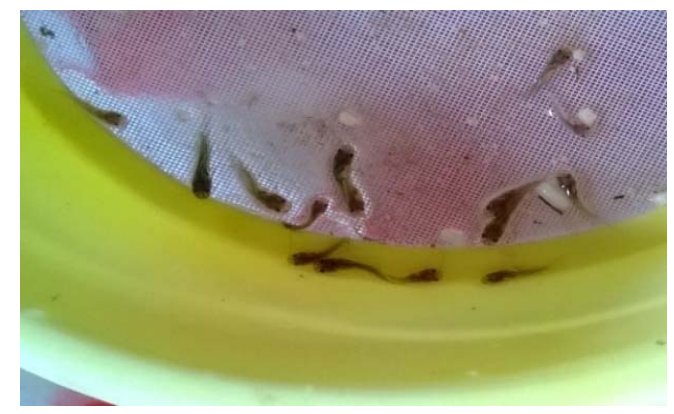

Fig 3: Pairing after injection

Fig 4: $15^{\text {th }}$ day fry

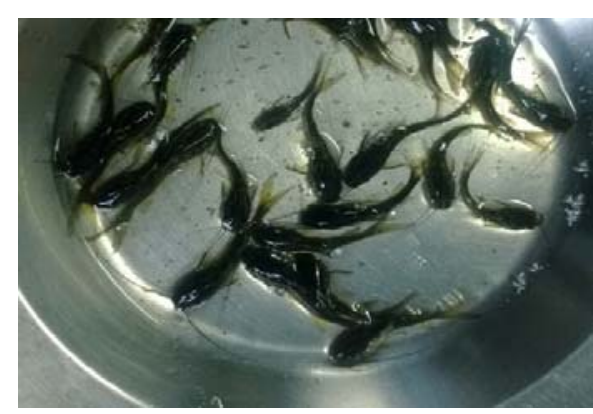

Fig 5: Fingerlings

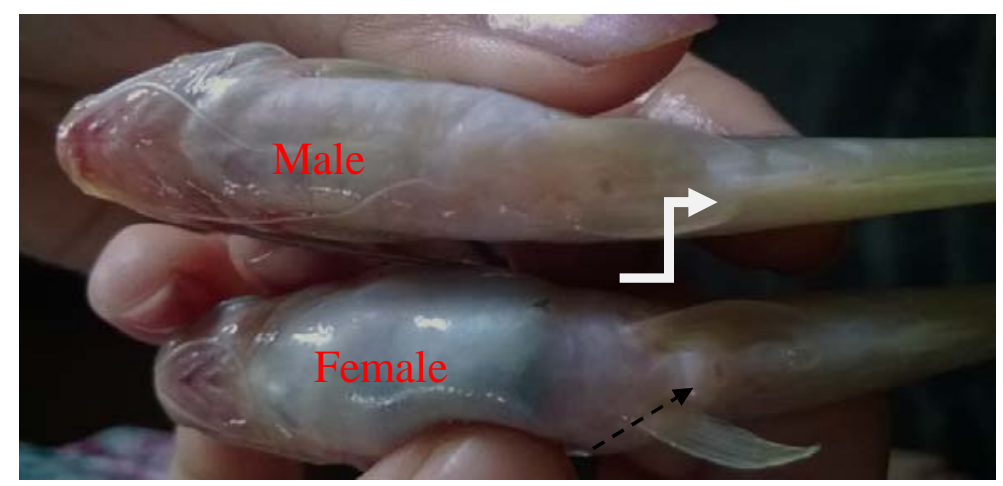


bioRxiv preprint doi: https://doi.org/10.1101/229377; this version posted December 5, 2017. The copyright holder for this preprint (which was not certified by peer review) is the author/funder, who has granted bioRxiv a license to display the preprint in perpetuity. It is made available under aCC-BY-ND 4.0 International license.

Fig 6: Sexual dimorphism in M. dibrugarensis 